\title{
Enhancement of luminous efficiency by hybrid structure for warm white light-emitting diodes
}

\author{
Chin-Wei Sher ${ }^{1}$, Kuo-Ju Chen², Chien-Chung Lin, Hau-Vei Han² ${ }^{3}$ Bing-Cheng Lin², Kuan-Yu Wang ${ }^{3}$, Jie-Ru Li ${ }^{2}$, \\ Mei-Tan Wang ${ }^{4}$, Jung-Min Hwang ${ }^{4}$, Min-Hsiung Shih ${ }^{2,5}$, Chien-Chung Fu ${ }^{1}$ and Hao-Chung Kuo ${ }^{2^{*}}$
}

\author{
* Correspondence: \\ hckuo@faculty.nctu.edu.tw \\ 2Department of Photonics \& \\ Institute of Electro-Optical \\ Engineering, National Chiao Tung \\ University, 1001 University Road, \\ Hsinchu 30010, Taiwan \\ Full list of author information is \\ available at the end of the article
}

\begin{abstract}
This study demonstrates the hybrid structure with high lumen efficiency and uniform angular-dependent correlated color temperature (CCT) for warm white LED. Compared to the conventional structures, the hybrid structure combines the advantage of the two different fabrication methods including dispense and pulse spray method together, which can produce the high quality lighting source. The experimental results indicate that the hybrid structure yielded higher lumen efficiency than conventional phosphor structure because of the gradual refractive index difference from the coating layer to the dispense layer. Moreover, the CCT deviations of the hybrid phosphor structure could be reduced to $65 \mathrm{~K}$ in range of -70 to 70 degrees. This is attributed to the uniform color mixing of the blue, yellow and red band in the hybrid phosphor structure. In addition, the chromaticity coordinate shift compared to the hybrid structure with the dispense structure are almost the same at a current regulation from $20 \mathrm{~mA}$ to $500 \mathrm{~mA}$. We believe that the technology of the hybrid structure with high lumen efficiency and uniform angular-dependent CCT is suitable for in the general lighting application.
\end{abstract}

Keywords: White light-emitting diodes; Hybrid; Phosphor; Package

\section{Background}

Recently, white light-emitting diodes (WLEDs) have been widely applied in the daily life because of their advantages of the small size, high efficiency, and long lifetime, which can be categorized as the environment-friendly lighting sources [1-3]. To date, the phosphor-converted white LED is the main approach by using the concept of the complementary colour to fabricate the white light [4]. Thus, the combination of the blue chip with the phosphor dominates most part of the solid-state lighting (SSL) market $[5,6]$. In the past decade, there have been many studies focused on enhancing the characteristic of the GaN-based blue chip including the internal quantum efficiency [7], efficiency droop [8] and light extraction $[9,10]$. Furthermore, the air voids $/ \mathrm{SiO}_{2}$ nanomasks and nanopillar substrates are employed to improve the crystalline quality of the GaN-based epilayer and increase the output efficiency [11,12]. Other than the performance of the blue chip, external package can also play an important part in terms of lumen enhancement. In general lighting application, the usage of blue chips and various phosphor materials can generate the two types of white lights: cool and warm WLEDs [13]. For the cool WLED at approximately $5000 \sim 5500 \mathrm{~K}$, the YAG:Ce

\section{Springer}


phosphor is used to generate the yellow light when pumped by blue source [14]. To achieve the warm WLED at approximately $2700 \sim 3000 \mathrm{~K}$, the red phosphor such as nitride-based phosphor is adopted in package and past results have delivered high color-rendering index (CRI) devices [15,16]. However, the red phosphor suffered from the larger stoke shift and causes the cascade excitation process in warm WLEDs, resulting in lower lumen efficiency [17]. To enhance the luminous flux for the warm white LED, the multi-layered phosphor configuration is used to enhance the luminous flux due to its higher phosphor conversion efficiency [18]. Moreover, Li et.al indicated that the conformal-shaped phosphor configuration can achieve high CRI LEDs with lower correlated color temperature (CCT) [19]. The conformal phosphor structure can generate the highly uniform light source with homogenous distribution of angular CCT [20]. However, for the conformal-type phosphor structure, there are $60 \%$ backscattering lights reflected to the package [21] and these back-scattering photons are susceptible to reabsorption by the blue chip and thus reducing the luminous efficiency. To solve these problems, the hybrid structure [22] and the dual-layer phosphor structure [23] are employed to enhance the lumen output due to the reduced back light inside the package. From these past experiences, therefore, it is essential to reduce the backscattering light issue when the concentration of the phosphor increased, especially in the warm white LED.

In this study, a hybrid structure is proposed to enhance the light output for warm white LED compared to a conventional phosphor structure at the same CCT. The experimental results indicate that the hybrid structure yielded higher lumen efficiency than mixed and conformal phosphor structure, due to higher lamination intensity at yellow and red bands. Moreover, the CCT deviation of the hybrid structure is approximately the same with the conventional structures, which is beneficial for future application of solid state lighting.

\section{Methods}

In this experiment, the hybrid structure was fabricated using the pulse spray coating method and dispensing method [24]. Figure 1 shows the schematic diagram of different types of samples in this experiment: (a) dispense (b) red-yellow coating (c) yellow-red

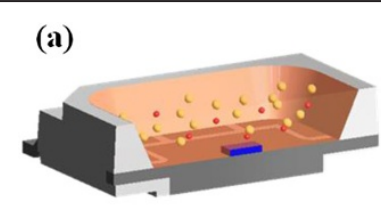

(d)

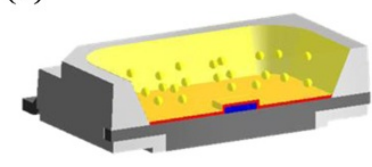

(b)

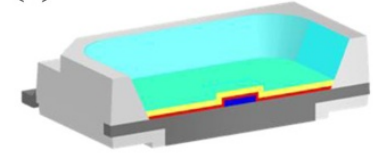

(e)

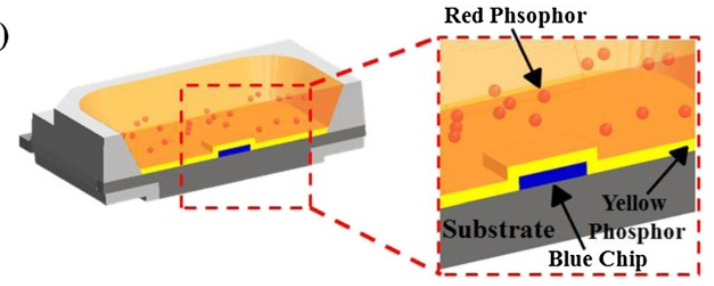

(c)

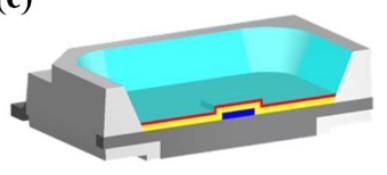

Red Phsophor

Figure 1 Schematic diagram of five type packaging methods: (a) dispense (b) red-yellow coating (c) yellow-red coating (d) red-yellow hybrid (e) yellow-red hybrid phosphor structures. 
Table 1 The concentration of the yellow and red phosphor at different packages

\begin{tabular}{cccccc}
\hline Package & Dispense & $\begin{array}{c}\text { Red-yellow } \\
\text { coating }\end{array}$ & $\begin{array}{c}\text { Yellow-red } \\
\text { coating }\end{array}$ & $\begin{array}{c}\text { Red-yellow } \\
\text { hybrid }\end{array}$ & $\begin{array}{c}\text { Yellow-red } \\
\text { hybrid }\end{array}$ \\
\hline Red phosphor concentration (\%) & 1.5 & 50 & 50 & 50 & 2 \\
Yellow phosphor concentration (\%) & 6 & 50 & 50 & 5 & 50 \\
\hline
\end{tabular}

coating (d) red-yellow hybrid (e) yellow-red hybrid phosphor structure. Our process flow can be described as follows: First, blue LED chips with peak emission wavelength of $450 \mathrm{~nm}$ are placed in the plastic lead-frame package. Then, the gold-wire bonding method was used to connect the positive and negative pads. The radiant fluxes of bare blue LED chips with size of $600 \mu \mathrm{m} \times 600 \mu \mathrm{m}$ were $120 \mathrm{~mW}$ at driving current $120 \mathrm{~mA}$. Second, the yellow and red phosphor are mixed with silicone encapsulant to fabricate the structure for dispensing method. For the red-yellow coating and yellowred coating phosphor structure, the pulse spray coating (PSC) method is employed to spray the phosphor film layer by layer onto the lead-frame package. For the hybrid phosphor structure, the phosphor film is sprayed on the lead-frame package by PSC method. After that, the phosphor powders were then blended with silicone and dispensed onto the lead frame. In this experiment, these LED with different structures are adjusted to fit the requirement of the warm white CCT. Furthermore, the phosphor powder used in the experiment were YAG:Ce ${ }^{3+}$ and $\mathrm{CaAlSiN}_{3}: \mathrm{Eu}^{2+}$ for the yellow and red emission, which is purchased from Intematix and Mitsubishi Chemical Corporation. The LED blue chip and silicone purchased from Epistar Corporation and Dow Corning Silicone. The refractive index of the phosphor and the silicone is approximately 1.8 and 1.53, respectively. Table 1 shows the concentration of the yellow and red phosphor at different packages. The particle size of the yellow phosphor and red phosphor is about $13 \mu \mathrm{m}$ and $10 \mu \mathrm{m}$.

\section{Results and discussion}

Figure 2 shows the PL and PL emission (PLE) spectra for the yellow and red phosphors. The PL spectra were measured under $450 \mathrm{~nm}$ excitation sources, whose wavelength is

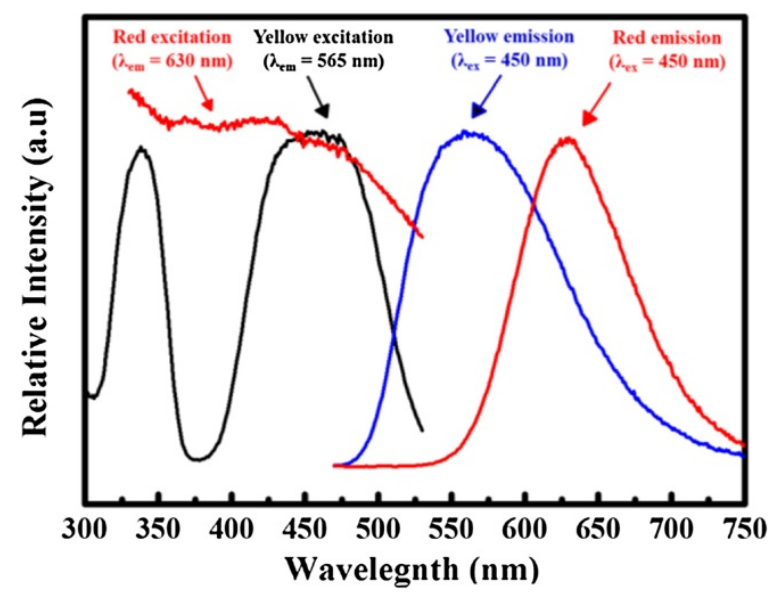

Figure 2 The intensity of yellow $\left(\mathrm{Y}_{3} \mathrm{Al}_{5} \mathrm{O}_{12}: \mathrm{Ce}^{3+}\right)$ and red $\left(\mathrm{CaAlSiN}_{3}: \mathrm{Eu}^{2+}\right)$ phosphors. 
the same as the blue LED chip. The PL emission bands of the yellow and red phosphors is located as $565 \mathrm{~nm}$ and $630 \mathrm{~nm}$, respectively and the full-widths at halfmaximun (FWHM) of the yellow and red phosphors are $120 \mathrm{~nm}$ and $90 \mathrm{~nm}$, respectively. From the PL and PLE spectra, it is obvious that the PLE spectrum of the red phosphor overlaps with the PL spectrum of the yellow phosphor, which can produce the reabsorption situation between yellow and red photons. Therefore, how to reduce the reabsorption effect become an important issue in the warm white LED. Reference [25] discussions clearly demonstrate that when the hybrid structure is stacked close to the LED chip more red light will be emitted resulting an considerable red-shifted phosphor spectrum of multilayer N-Y LEDs. From the experiment results, the yellow-red coating structure shows the higher lumen efficiency than the red-yellow coating structure. It can be explained by the efficiency of pumping because the yellow-red coating has a better arrangement on the pumping. In the red-yellow coating, the blue photons will be absorbed by the red phosphors first, and fewer yellow phosphors will get pumped to emit yellow photons. The overall converted photons are thus less than the previous case because the red photons cannot pump the yellow phosphors. However, for this two hybrid phosphor structure, the two layouts are almost the same in luminous flux, mainly due to the upper layer of the phosphors are away from the chip. So the backscattering and re-absorption issues are much less severe in both layouts. Thus the luminous fluxes are almost the same. The slightly stronger output from the yellowred hybrid should stem from the higher portion of yellow photons received by the detector which can increase the lumen readings.

The emission spectra of dispense, coating and hybrid phosphor structure are shown in Figure 3(a). These structures had the same CCT at approximately $3000 \mathrm{~K}$, and all operated at a current of $120 \mathrm{~mA}$ and thus the excitation power to all types of structures is $120 \mathrm{~mW}$. From the emission spectra, the hybrid structure produced a higher intensity in yellow components for red-yellow hybrid and yellow-red hybrid phosphor structure. Figure 3(b) shows luminous flux of the dispense, coating and hybrid phosphor structure driven at currents from 20 to $500 \mathrm{~mA}$. Moreover, the luminous flux of the five type packaging methods at $120 \mathrm{~mA}$ is shown in Table 2. The red-yellow hybrid phosphor structure exhibits a $4.7 \%, 19.4 \%$ and $6 \%$ lumen enhancement over the conventional dispense, the red-yellow coating and yellow-red coating phosphor structure. As the driving current increased, the lumen output differences between the hybrid, dispense and the
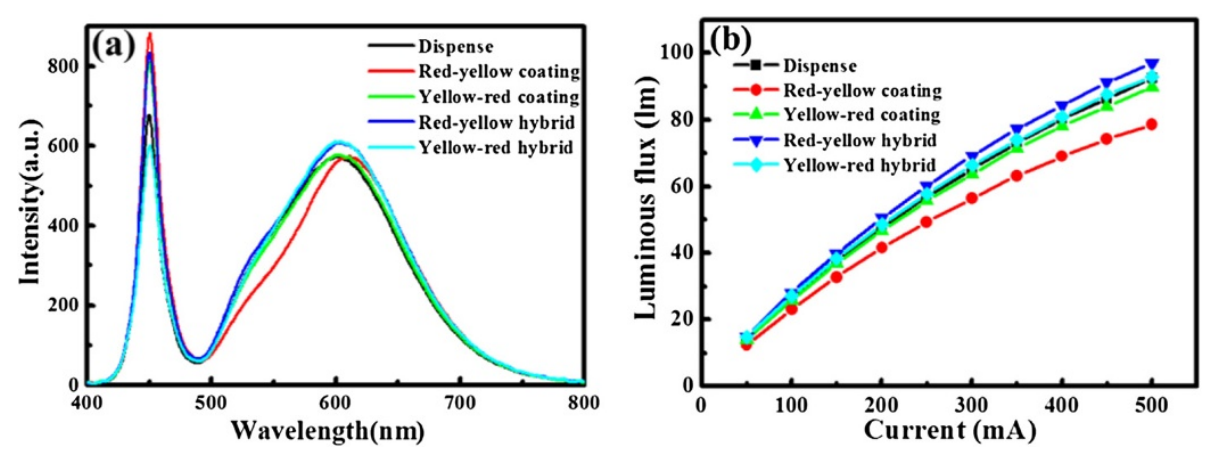

Figure 3 The dispense, coating and hybrid phosphor structure driven at currents from 20 to 500 mA. (a) Emission spectra (b) Luminous flux. 
Table 2 The luminous flux of the five type packaging methods

\begin{tabular}{cccccc}
\hline Package & Dispense & $\begin{array}{c}\text { Red-yellow } \\
\text { coating }\end{array}$ & $\begin{array}{c}\text { Yellow-red } \\
\text { coating }\end{array}$ & $\begin{array}{c}\text { Red-yellow } \\
\text { hybrid }\end{array}$ & $\begin{array}{c}\text { Yellow-red } \\
\text { hybrid }\end{array}$ \\
\hline Luminous flux $(\mathrm{Im})$ & 31.7 & 27.8 & 31.3 & 33.2 & 32.8 \\
\hline
\end{tabular}

coating structures become larger. Moreover, the advantage of the hybrid structure could provide the gradual refractive index difference from the coating layer to the dispense layer and reduce the reflection loss in the interface [22]. Therefore, the hybrid structure has the higher luminous efficiency than the dispense and coating structures.

Figure 4 shows the angular-dependent CCTs of dispense, coating and hybrid phosphor structure. To evaluate the light quality for white LED, the difference of angular CCT deviation between the normal and large angle is an important standard to evaluate in the SSL application [26]. The larger CCT deviation would lead to the yellow ring phenomenon and generate the non-uniform white color at the different angle [27]. The definition of the CCT deviation is calculated as follows [26]:

$$
\triangle C C T=C C T(\operatorname{Max})-C C T(\operatorname{Min}),
$$

where $\mathrm{CCT}$ (Max) and $\mathrm{CCT}(\mathrm{Min})$ represent the maximal $\mathrm{CCT}$ at the zero degree of viewing angle and minimal $\mathrm{CCT}$ at the 70 degree of viewing angle, respectively. Generally, the CCT deviation of the warm white LED is smaller than the cool white LED because the light pass through the higher phosphor concentration in the warm white CCT and the different light could be well mixed, leading to the uniform white light [28]. The CCT deviations of dispense, coating and hybrid phosphor structure is shown in Figure 4 (a). The CCT deviations of the red-yellow hybrid and yellow-red hybrid phosphor structure were $126 \mathrm{~K}$ and $65 \mathrm{~K}$, which is slightly higher than the dispense and coating phosphor structure. However, these values are still good enough for the warm white LED in the solid-state lighting source. Moreover, Figure 4 (b-c) shows the far field picture of red-yellow hybrid and yellow-red hybrid phosphor structure and it is obvious that the hybrid structures can exhibit the uniform light.

For the white LED, the color deviation with the different current is used to evaluate the color stability for high-quality lighting applications. Therefore, the chromaticity coordinate shift of the dispense, coating and hybrid phosphor structure at various driving

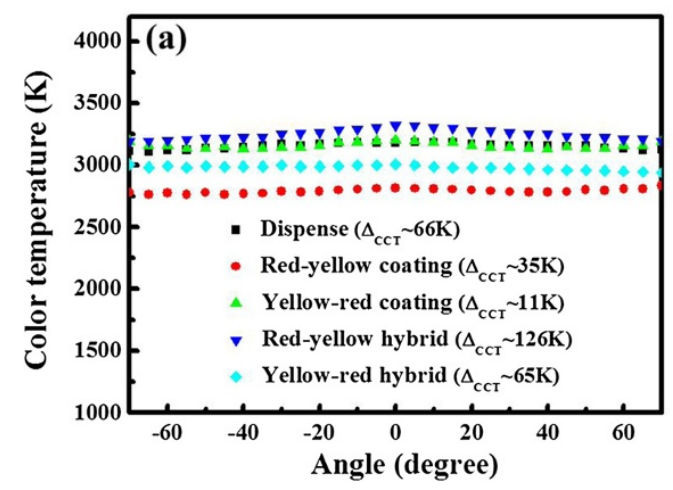

(b)

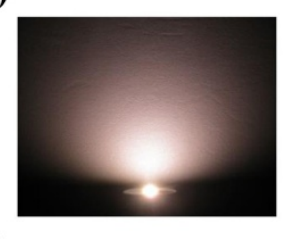

(c)

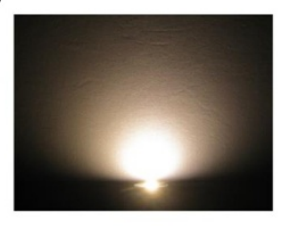

Figure 4 The dispense, coating and hybrid phosphor structure. (a) The angular-dependent correlated color temperature $(\mathbf{b}-\mathbf{c})$ The far field picture of red-yellow hybrid and yellow-red hybrid phosphor structure. 


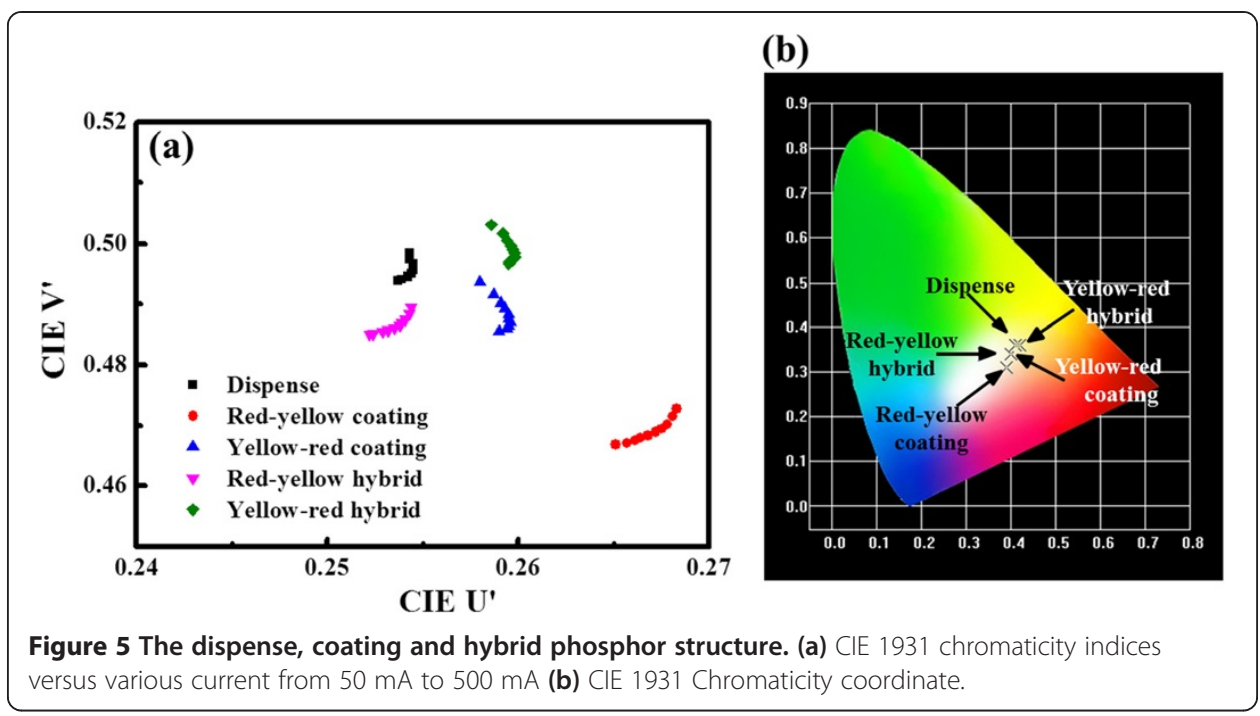

currents from $20 \mathrm{~mA}$ to $500 \mathrm{~mA}$ are shown in Figure 5(a). With the increased current, the chromaticity coordinates for both samples move to the blue region. Moreover, the color deviation of a lighting system, $\left(\Delta u^{\prime} v^{\prime}\right)$ is calculated as follows [29]:

$$
\begin{aligned}
& u^{\prime}=4 x /(-2 x+12 y+3) \\
& v^{\prime}=9 y /(-2 x+12 y+3) \\
& \Delta u^{\prime} v^{\prime}=\sqrt{\left(\Delta u^{\prime}\right)^{2}+(\Delta v)^{2}}
\end{aligned}
$$

where $u^{\prime}, v^{\prime}$ is the chromaticity coordinates in the CIE 1976 diagram, and $\mathrm{x}$ and $\mathrm{y}$ are the chromaticity coordinates in the CIE 1931 diagram. The $\Delta u^{\prime} v^{\prime}$ value indicates spatial color uniformity in (4). Figure 5(a) shows the color chromaticity coordinate deviations at various ambient temperatures from $20 \mathrm{~mA}$ to $500 \mathrm{~mA}$. The experimental value $\left(\Delta u^{\prime} v^{\prime}\right)$ indicates that the color deviation value of the red-yellow hybrid and yellowred hybrid phosphor structure were 0.005 and 0.0065 , which is nearly the same as other structures, as shown in Table 3. Consequently, both red-yellow hybrid and yellow-red hybrid phosphor structure results in stable CCT stability and high-quality warm white source.

Another important characteristic of WLEDs is color rendering index (CRI). This index evaluates how different colors look like in the light. Figure 6 shows CRI value of dispense, red-yellow coating, yellow-red coating, red-yellow hybrid and yellow-red hybrid phosphor structure at various Munsell codes. The CRI value is calculated by taking the average color rendering of each Munsell codes [30]. Higher CRI value means the better light quality when compared to natural light source, and this is an important standard for general lighting purpose [31]. The CRI of the proposed red-yellow hybrid

Table 3 The CCT deviation of the five type packaging methods

\begin{tabular}{cccccc}
\hline Package & Dispense & $\begin{array}{c}\text { Red-yellow } \\
\text { coating }\end{array}$ & $\begin{array}{c}\text { Yellow-red } \\
\text { coating }\end{array}$ & $\begin{array}{c}\text { Red-yellow } \\
\text { hybrid }\end{array}$ & $\begin{array}{c}\text { Yellow-red } \\
\text { hybrid }\end{array}$ \\
\hline Chromaticity coordinate shift $\left(\Delta u^{\prime} v^{\prime}\right)$ & 0.0047 & 0.0067 & 0.0082 & 0.005 & 0.0065 \\
\hline
\end{tabular}




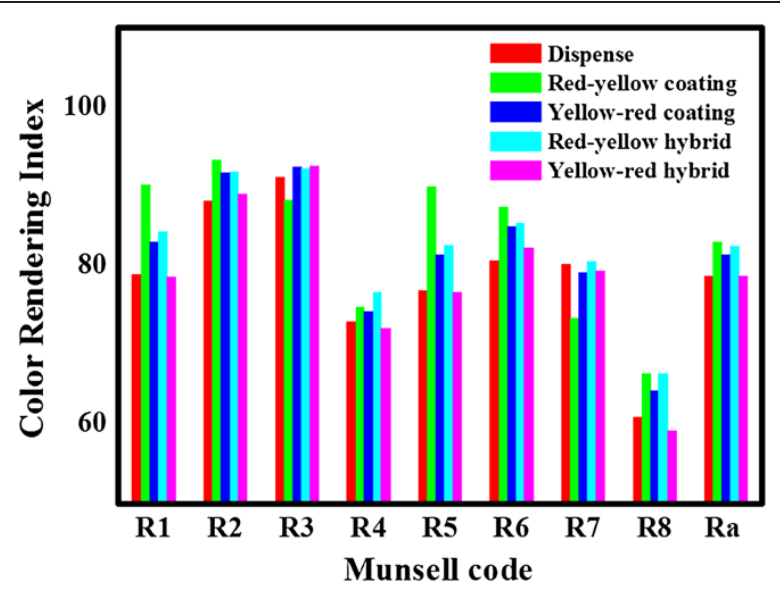

Figure 6 CRI of dispense, red-yellow coating, yellow-red coating, red-yellow hybrid and yellow-red hybrid phosphor structure at various Munsell codes.

warm white LED could achieve 82.4 and this high value meets the CRI requirement for future SSL application (with CRI >80) [32]. Therefore, the technology of red-yellow hybrid phosphor structure with higher lumen output and better CRI value provides an alternative approach to use for the lighting source.

\section{Conclusion}

In this study, the hybrid phosphor structure with high lumen efficiency and uniform angular-dependent CCT is demonstrated for the warm white LED. It is found that the hybrid structure could provide the suitable refractive index difference from the coating layer to the dispense layer, resulting in the higher lumen efficiency. For the light quality, both red-yellow hybrid and yellow-red hybrid phosphor structure demonstrates the uniform color temperature in range of -70 to 70 degrees. Moreover, the chromaticity coordinate shift of the hybrid structure and the dispense structure are almost the same from $20 \mathrm{~mA}$ to $500 \mathrm{~mA}$ of driving currents. Compare with red-yellow coating structure and yellow-red coating structure. Yellow-red coating structure's efficiency is higher. We think the reason is Yellow-red coating structure can reduce stroke shift effect. In this study, we find that the red-yellow coating structure can reduce yellow's absorb percentage. Hybrid structure can reduce the back scatting effect. It is mean the hybrid structure is better than phosphor coating structure. The reason for higher efficiency hybrid structure is reduce back scattering and reduce reabsorption.

Through the hybrid phosphor package type, the finished LEDs could achieve high efficiency and high CRI which are essential features for a high quality solid state lighting source.

\section{Abbreviations \\ WLEDs: White light-emitting diodes; SSL: Solid-state lighting; CRI: Color-rendering index; CCT: Correlated color temperature; PSC: Pulse spray coating; PLE: PL excitation.}

Competing interests

The authors declare that they have no competing interests. 
the process of the experiment and participated in the discussion. KYW fabricated all the samples and measured the optical characteristic and explained lumen flux and lumen efficiency. JRL participated in discuss of the study and measured the angular-dependent correlated color temperature and explained it. MTW participated in discuss of the study and analyzed electroluminescence. JMH participated in discuss of the study and analyzed CRI value. MHS participated in discuss of the study. CCF participated in discuss of the study. HCK participated in discuss of all the results. All authors read and approved the final manuscript.

\section{Acknowledgments}

The authors express their gratitude to EPISTAR Corporation and Helio Opto. Corporation for their technical support. This research was funded by the National Science Council, Taiwan (NSC101-3113-E-009 -002-CC2, NSC-99-2112-M-001033-MY3 and NSC-99-2120-M-009-007).

\section{Author details}

'Department of Power Mechanical Engineering, National Tsing Hua University, Taiwan R.O.C, No. 101, Section 2, Kuang-Fu Road, Hsinchu 30013, Taiwan. ${ }^{2}$ Department of Photonics \& Institute of Electro-Optical Engineering, National Chiao Tung University, 1001 University Road, Hsinchu 30010, Taiwan. ${ }^{3}$ Institute of Photonic System, National Chiao Tung University, 301 Gaofa 3rd Rd., Guiren Township, Tainan County 711, Taiwan. Intelligent Energy-Saving System Division, Green Energy \& Environment Research Laboratories, Industrial Technology Research Institute 195, Sec. 4, Chung Hsing Rd., Chutung, Hsinchu 31040, Taiwan. ${ }^{5}$ Research Center for Applied Sciences (RCAS), Academia Sinica, Nankang, Taipei 115, Taiwan.

Received: 29 January 2014 Accepted: 9 May 2014

Published: 14 July 2014

\section{References}

1. Schubert EF, Kim JK: Solid-state light sources getting smart. Science 2005, 308:1274-1278.

2. Chen KJ, Chen HC, Lin CC, Wang CH, Yeh CC, Tsai HH, Chien SH, Shih MH, Kuo HC: An investigation of the optical analysis in white light-emitting diodes with conformal and remote phosphor structure. J Disp Technol 2013, 9:915-920.

3. Pimputkar S, Speck JS, DenBaars SP, Nakamura S: Prospects for LED lighting. Nat Photonics 2009, 3:179-181.

4. Chen KJ, Kuo HT, Chen HC, Shih MH, Wang CH, Chien SH, Chiu SH, Lin CC, Pan CJ, Kuo HC: High thermal stability of correlated color temperature using current compensation in hybrid warm white high-voltage LEDs. Opt Express 2013, 21:A201-A207.

5. Kuo HC, Hung CW, Chen HC, Chen K, Wang CH, Sher CW, Yeh CC, Lin CC, Chen CH, Cheng YJ: Patterned structure of REMOTE PHOSPHOR for phosphor-converted white LEDs. Opt Express 2011, 19:A930-A936.

6. Chen HC, Chen KJ, Wang CH, Lin CC, Yeh CC, Tsai HH, Shih MH, Kuo HC, Lu TC: A novel randomly textured phosphor structure for highly efficient white light-emitting diodes. Nanoscale Res Lett 2012, 7:1-5.

7. Lin DW, Huang JK, Lee CY, Chan RW, Lan YP, Lin CC, Lee KY, Lin CH, Lee PT, Chi GC, Kuo HC: Enhanced light output power and growth mechanism of GaN-based light-emitting diodes grown on cone-shaped $\mathrm{SiO} 2$ patterned template. J Disp Technol 2013, 9:285-291.

8. Wang CH, Ke CC, Lee CY, Chang SP, Chang WT, Li JC, Li ZY, Yang HC, Kuo HC, Lu TC, Wang SC: Hole injection and efficiency droop improvement in InGaN/GaN light-emitting diodes by band-engineered electron blocking layer. Appl Phys Lett 2010, 97:261103.

9. Wuu DS, Wang WK, Wen KS, Huang SC, Lin SH, Huang SY, Lin CF, Horng RH: Defect reduction and efficiency improvement of near-ultraviolet emitters via laterally overgrown GaN on a GaN/patterned sapphire template. Appl Phys Lett 2006, 89:161105.

10. Lee YJ, Hwang JM, Hsu TC, Hsieh MH, Jou MJ, Lee BJ, Lu TC, Kuo HC, Wang SC: Enhancing the output power of GaN-based LEDs grown on wet-etched patterned sapphire substrates. IEEE Photonic Tech L 2006, 18:1152-1154.

11. Chiu CH, Lin CC, Han HV, Liu CY, Chen YH, Lan YP, Yu P, Kuo HC, Lu TC, Wang SC, Chang CY: High efficiency GaN-based light-emitting diodes with embedded air voids/SiO 2 nanomasks. Nanotechnology 2012, 23:045303.

12. Chiu CH, Tu PM, Lin CC, Lin DW, Li ZY, Chuang KL, Chang JR, Lu TC, Zan HW, Chen CY, Kuo HC, Wang SC, Chang CY: Highly efficient and bright leds overgrown on Gan nanopillar substrates. IEEE J Sel Top Quant 2011, 17:971-978.

13. Lai CF, Chang CC, Wang MJ, Wu MK: CCT- and CRI-tuning of white light-emitting diodes using threedimensional non-close-packed colloidal photonic crystals with photonic stopbands. Opt Express 2013, 21: A687-A694.

14. Park HK, Oh JH, Do YR: Toward scatter-free phosphors in white phosphor-converted light-emitting diodes. Opt Express 2012, 20:10218-10228.

15. Chen KJ, Chen HC, Tsai KA, Lin CC, Tsai HH, Chien SH, Cheng BS, Hsu YJ, Shih MH, Tsai CH, Shih HH, Kuo HC: Resonant-enhanced full-color emission of quantum-dot-based display technology using a pulsed spray method. Adv Funct Mater 2012, 22:5138-5143.

16. Won YH, Jang HS, Cho KW, Song YS, Leon DY, Kwon HK: Effect of phosphor geometry on the luminous efficiency of high-power white light-emitting diodes with excellent color rendering property. Opt Lett 2009, 34:1-3.

17. Fukui T, Kamon K, Takeshita J, Hayashi H, Miyachi T, Uchida Y, Kurai S, Taguchi T: Superior illuminant characteristics of color rendering and luminous efficacy in multilayered phosphor conversion white light sources excited by near-ultraviolet light-emitting diodes. Jpn J Appl Phys 2009, 48:112101.

18. You JP, Tran NT, Shi FG: Light extraction enhanced white light-emitting diodes with multi-layered phosphor configuration. Opt Express 2010, 18:5055-5060. 
19. Li ZT, Tang Y, Liu ZY, Tan YE, Zhu BM: Detailed study on pulse-sprayed conformal phosphor configurations for LEDs. J Disp Technol 2013, 9:433-440.

20. Chen HC, Chen KJ, Lin CC, Wang CH, Han HV, Tsai HH, Kuo HT, Chien SH, Shih MH, Kuo HC: Improvement in uniformity of emission by $\mathrm{ZrO}_{2}$ nano-particles for white LEDs. Nanotechnology 2012, 23:265201.

21. Narendran N, Gu Y, Freyssinier-Nova JP, Zhu Y: Extracting phosphor-scattered photons to improve white LED efficiency. Phys Status Solidi A 2005, 202:R60-R62.

22. Chen KJ, Han HV, Lin BC, Chen HC, Shih MH, Chien SH, Wang KY, Tsai HH, Yu P, Lee PT, Lin CC, Kuo HC: Improving the angular color uniformity of hybrid phosphor structures in white light-emitting diodes. IEEE Electr Device L 2013, 34:1280-1282.

23. Chen KJ, Chen HC, Shih MH, Wang CH, Tsai HH, Chien SH, Lin CC, Kuo HC: Enhanced luminous efficiency of WLEDs using a dual-layer structure of the remote phosphor package. J Lightwave Technol 2013, 31:1941-1945.

24. Chen KJ, Han HV, Chen HC, Lin CC, Chien SH, Huang CC, Chen TM, Shih MH, Kuo HC: White light emitting diodes with enhanced CCT uniformity and luminous flux using ZrO2 nanoparticles. Nanoscale 2014, 6:5378-5383.

25. Li Zong T, Tang Y, Liu Z-Y, Tan Y-E, Zhu B-M: Detailed study on pulse-sprayed conformal phosphor configurations for LEDs. IEEE J Disp Technol 2013, 6:433-440.

26. Shuai Y, He Y, Tran NT, Shi FG: Angular CCT uniformity of phosphor converted white LEDs: effects of phosphor materials and packaging structures. IEEE Photonic Tech L 2011, 23:137-139.

27. Huang KC, Lai TH, Chen CY: Improved CCT uniformity of white LED using remote phosphor with patterned sapphire substrate. Appl Optics 2013, 52:7376-7381.

28. Sun CC, Chen CY, Chen CC, Chiu CY, Peng YN, Wang YH, Yang TH, Chung TY, Chung CY: High uniformity in angular correlated-color-temperature distribution of white LEDs from $2800 \mathrm{~K}$ to $6500 \mathrm{~K}$. Opt Express 2012 , 20:6622-6630.

29. Huang HT, Tsai CC, Huang YP: Conformal phosphor coating using pulsed spray to reduce color deviation of white LEDs. Opt Express 2010, 18:A201-A206.

30. Nizamoglu S, Erdem T, Sun XW, Demir HV: Warm-white light-emitting diodes integrated with colloidal quantum dots for high luminous efficacy and color rendering. Opt Lett 2010, 35:3372-3374.

31. Erdem T, Nizamoglu S, Sun XW, Demir HV: A photometric investigation of ultra-efficient LEDs with high color rendering index and high luminous efficacy employing nanocrystal quantum dot luminophores. Opt Express 2010, 18:340-347.

32. Nizamoglu S, Zengin G, Demir HV: Color-converting combinations of nanocrystal emitters for warm-white light generation with high color rendering index. Appl Phys Lett 2008, 92:031102.

doi:10.1186/2196-1107-1-9

Cite this article as: Sher et al:: Enhancement of luminous efficiency by hybrid structure for warm white

light-emitting diodes. Journal of Solid State Lighting 2014 1:9.

\section{Submit your manuscript to a SpringerOpen ${ }^{\circ}$ journal and benefit from:}

- Convenient online submission

- Rigorous peer review

- Immediate publication on acceptance

- Open access: articles freely available online

- High visibility within the field

- Retaining the copyright to your article

Submit your next manuscript at $\boldsymbol{\sim}$ springeropen.com 